Received: 21 September 2020

Revised: 30 November 2020

Accepted: 18 Desember 2020

Published: 31 Desember 2020

\title{
Analisis Faktor-Faktor yang Memengaruhi Kompetensi Karyawan SOS Children's Villages Indonesia
}

\author{
Anis Dela Desela ${ }^{1, a)}$, Rianti Setiadi $^{1, b)}$, Yekti Widyaningsih ${ }^{1, c)}$ \\ ${ }^{1}$ Departemen Matematika, Fakultas Matematika dan Ilmu Pengetahuan Alam, Universitas Indonesia, Depok \\ a)anis.dela@sci.ui.ac.id \\ b)rianti@sci.ui.ac.id \\ ${ }^{c}$ corresponding author : widyaningsihyekti@gmail.com
}

\begin{abstract}
Economic and social growth in a country are inseparable from the role of Non-Governmental Organization (NGO). However, various problems occur in NGO. To overcome problems and improve the service quality, NGO is expected to have employees with high competency. The study was conducted at SOS Children's Villages Indonesia which is one of the NGO in Indonesia focused on supporting children without parental care and families at risk. The purpose of this study is to find out the factors that affecting employee competency at SOS Children's Villages Indonesia and to find out the profiles of employees with high competency. The analytical methods used in this study are Partial Least Square and Classification and Regression Tree. The results showed that the variables which significantly affected competency were interpersonal and creativity variables. The result of profile analysis for employees with high competency showed that employees who work in Fund Development and Communication office located in Bandung or DKI Jakarta, or employees who work in National Office located in Bandung with high level of creativity tend to have high competency, in addition the employees who work in Fund Development and Communication office located in Bandung, despite having a low level of interpersonal and creativity, the employees have a tendency to have high competency.
\end{abstract}

Keywords: Classification and Regression Tree, Non-Governmental Organization, Partial Least Square

\begin{abstract}
Abstrak
Pertumbuhan ekonomi dan sosial di suatu negara tidak terlepas dari peran Non-Governmental Organization (NGO). Akan tetapi, terdapat beberapa permasalahan yang muncul dari NGO. Untuk menanggulangi permasalahan dan meningkatkan kualitas pelayanan, suatu NGO diharapkan memiliki karyawan dengan kompetensi tinggi. Penelitian dilakukan di SOS Children's Villages Indonesia yang merupakan salah satu NGO di Indonesia yang didedikasikan untuk anak-anak yang telah atau berisiko kehilangan pengasuhan orang tua. Tujuan dari penelitian ini adalah untuk mengetahui faktor-faktor yang memengaruhi kompetensi karyawan di SOS Children's Villages Indonesia serta mengetahui profil dari karyawan dengan kompetensi tinggi. Metode analisis yang digunakan dalam penelitian ini adalah Partial Least Square dan Classification and Regression Tree. Hasil penelitian menunjukkan bahwa variabel yang secara signifikan berpengaruh terhadap kompetensi adalah variabel interpersonal dan kreativitas. Hasil
\end{abstract}


analisis profil untuk karyawan dengan kompetensi tinggi menunjukkan bahwa karyawan yang bekerja di kantor Fund Development and Communication yang terletak di Bandung atau DKI Jakarta, atau karyawan yang bekerja di kantor National Office yang terletak di Bandung dengan tingkat kreativitas tinggi cenderung memiliki kompetensi yang tinggi, selain itu karyawan yang bekerja di kantor Fund Development and Communication yang terletak di Bandung meskipun memiliki tingkat interpersonal dan kreativitas rendah, karyawan tersebut memiliki kecenderungan untuk memiliki kompetensi tinggi.

Kata-kata kunci: Classification and Regression Tree, Non-Governmental Organization, Partial Least Square

\section{PENDAHULUAN}

Non-Governmental Organization (NGO) merupakan organisasi nirlaba yang memiliki tujuan tertentu. Tujuan dari NGO seringkali berupa advokasi mengenai permasalahan atau isu sosial yang ada di negara tersebut, contohnya adalah untuk pengasuhan anak, kepedulian lingkungan, korupsi, hak asasi manusia, dan lainnya. Pertumbuhan ekonomi dan sosial di suatu negara tidak terlepas dari peran NGO. Keberadaan NGO di Indonesia juga turut membantu menopang pembangunan dan memelihara sistem demokratis (Herdiansah dan Randi, 2016). Selain manfaat yang dibawa oleh NGO, terdapat permasalahan yang muncul. Permasalahan tersebut berkisar pada kemampuan NGO untuk mempertanggungjawabkan pengelolaan keuangan yang dimiliki dan penggiatan aktivitas untuk tujuan organisasi. Untuk menanggulangi permasalahan dan meningkatkan kualitas pelayanan, penting bagi suatu NGO untuk memaksimalkan potensi dan peran dalam melakukan pekerjaan ataupun kegiatan bagi organisasi (Rajegunung, 2017). Penanggulangan permasalahan serta peningkatan kualitas pelayanan tentunya tidak terlepas dari sumber daya manusia atau karyawan yang dimiliki oleh organisasi. Suatu NGO diharapkan memiliki karyawan dengan kompetensi maksimum agar tujuan dari organisasi dapat tercapai. Kompetensi merupakan karakteristik yang mendasari seseorang untuk menciptakan hasil kinerja yang efektif dan atau performa yang unggul dalam pekerjaan (Klemp (1980) dalam Chouhan dan Srivastava, 2016). Karyawan yang memiliki kompetensi tinggi dapat menghasilkan dampak yang baik bagi organisasi, sehingga organisasi dapat melakukan pengelolaan keuangan dengan baik, melakukan aktivitas organisasi, dan meningkatkan pelayanan, sehingga organisasi dapat mencapai tujuannya.

Berdasarkan pertimbangan tersebut, peneliti berpendapat bahwa perlu diadakan penelitian mengenai kompetensi pada karyawan di suatu Non-Governmental Organizations (NGO). Penelitian dilakukan pada karyawan SOS Children's Villages Indonesia. SOS Children's Villages Indonesia merupakan salah satu organisasi nirlaba (NGO) di Indonesia yang didedikasikan untuk anak-anak yang telah atau berisiko kehilangan pengasuhan keluarga (SOS Children's Villages, n.d.). Faktorfaktor yang dibutuhkan untuk meraih kompetensi dalam karir, diantaranya adalah berpikir kritis, memiliki kemampuan komunikasi oral ataupun tertulis, dapat bekerjasama, dan bersikap kepemimpinan (National Association of Colleges and Employers, 2019). Sebuah penelitian menunjukkan bahwa salah satu hal yang diperlukan dalam dunia usaha atau industri untuk kompetensi pada abad ke-21 adalah berpikir kritis (Wijaya, Sudjimat, \& Nyoto, 2016). Oleh karena itu, berpikir kritis diduga menjadi faktor yang memiliki pengaruh yang signifikan terhadap kompetensi pada karyawan di SOS Children's Villages Indonesia.

Seorang pemimpin menggunakan sifat kepemimpinannya untuk mengarahkan perusahaan dan karyawan untuk membangun masa depan mereka, karena ini adalah tanggung jawabnya untuk menemukan jalan baru dalam organisasi dan mengejar tujuan organisasi (Won-joo \& Mulhern (2009) dalam Almaki, 2016). Sebuah penelitian menunjukkan bahwa kepemimpinan secara signifikan berpengaruh positif terhadap kompetensi (Juanda, 2019). Keterampilan interpersonal merupakan kemampuan untuk menginspirasi orang lain, mengendalikan konflik, berkomunikasi secara efektif, dan membangun kerjasama tim (Quinn, 2013). Dengan memiliki keterampilan interpersonal, karyawan diharapkan dapat bekerja secara optimal tanpa adanya hambatan yang disebabkan oleh hubungan personal dengan karyawan lain. Alasan tersebut didukung oleh pernyataan bahwa keterampilan interpersonal penting bagi seseorang untuk menjadi sukses dalam kehidupan pribadi dan kehidupan profesionalnya (Vijayalakshmi, 2016). Keterampilan intrapersonal meningkatkan 
kepercayaan diri seseorang, sehingga orang tersebut lebih mudah untuk menjalin pertemanan dan bekerja secara efektif dengan orang lain, memiliki keberanian untuk mengambil tanggung jawab yang lebih besar, dan meningkatkan produktivitas. (Vijayalakshmi, 2016). Jika karyawan memiliki keterampilan intrapersonal, maka karyawan diduga dapat memahami dengan baik apa yang dirinya butuhkan, baik untuk bekerja secara efektif ataupun berhubungan dengan rekan kerja.

Kreativitas dan inovasi adalah langkah untuk meraih kesuksesan dalam persaingan antar organisasi atau perusahaan, serta meningkatkan keefektifan karyawan dalam lingkungan yang berubah secara dinamis (Szczepańska-Woszczyna, 2014). Organisasi atau perusahaan yang dapat menghasilkan pengetahuan, inovasi, dan perubahan melalui tindakan yang kreatif dapat membangun kompetensi yang memberikan keuntungan jangka panjang dibandingkan pesaing yang kurang kreatif (Michalik, 2017). Berdasarkan penjelasan tersebut, dapat dirangkum bahwa kompetensi dapat diukur dengan variabel berpikir kritis, kepemimpinan, interpersonal, intrapersonal, kreativitas, dan inovasi. Selain variabel yang telah disebutkan sebelumnya, peneliti juga tertarik untuk mencari profil dari karyawan dengan kompetensi tinggi. Variabel yang digunakan untuk mencari profil dari karyawan dengan kompetensi tinggi adalah variabel yang signifikan berpengaruh terhadap kompetensi, yang diperoleh dengan metode Partial Least Square, serta variabel demografi, yaitu tempat bekerja, usia, dan tingkat pendidikan.

Tersebarnya tempat bekerja atau kantor SOS Children's Villages Indonesia di beberapa provinsi di Indonesia, diduga memengaruhi kompetensi karyawan. Hal tersebut mungkin terjadi karena lingkungan kerja yang berbeda-beda. Berdasarkan studi yang dilakukan pada sebuah perusahaan, ditunjukkan bahwa lingkungan kerja secara signifikan memengaruhi produktivitas kerja karyawan (Istikomah, 2016). Usia produktif bagi tenaga kerja adalah usia 20 hingga 40 tahun (Ramadhan, 2013). Seseorang yang berada dalam usia produktif diharapkan mampu menghasilkan hasil kinerja efektif, oleh karena itu usia akan dilibatkan dalam mencari profil karyawan dengan kompetensi tinggi. Pendidikan dan pelatihan merupakan salah satu cara untuk memperoleh kompetensi (Spencer dan Spencer (1993) dalam Purnomo dan Sudana, 2016). Teori tersebut mendukung alasan diduganya terdapat pengaruh signifikan dari pendidikan terakhir terhadap kompetensi karyawan.

Berdasarkan pembahasan yang telah dijelaskan pada penjelasan di atas, hipotesis yang ditetapkan dalam penelitian ini adalah:

1. Terdapat pengaruh yang signifikan dari variabel berpikir kritis, kepemimpinan, interpersonal, intrapersonal, kreativitas, dan inovasi terhadap variabel kompetensi.

2. Dapat diketahui profil dari karyawan di SOS Children's Villages Indonesia dengan kompetensi yang tinggi berdasarkan variabel yang signifikan memengaruhi kompetensi, tempat bekerja, usia, dan tingkat pendidikan.

\section{METODOLOGI PENELITIAN}

\section{Data}

Data yang digunakan dalam penelitian ini merupakan data primer. Data menggunakan skala pengukuran interval. Pengambilan data dilakukan dengan membagikan kuesioner secara online kepada karyawan SOS Children's Villages Indonesia yang bekerja di kantor Fund Development and Communication dan kantor National Office. Kuesioner dibagikan mulai pada akhir bulan Februari 2020 hingga akhir bulan Maret 2020.

\section{Populasi dan Sampel}

Populasi yang digunakan dalam penelitian ini adalah karyawan SOS Children's Villages Indonesia yang bekerja di kantor Fund Development and Communication (FDC) yang terletak di DKI Jakarta, Bandung, DI Yogyakarta, Surabaya, Bali, serta kantor National Office (NO) yang terletak di Bandung.

Sampel dalam penelitian ini didapatkan dengan menggunakan teknik pengambilan sampel berupa purposive sampling. Peneliti menggunakan purposive sampling karena peneliti tidak memiliki kerangka sampel. Sampel terdiri dari 117 karyawan SOS Children's Villages Indonesia yang bekerja 
di kantor Fund Development and Communication dan kantor National Office yang bersedia mengisi kuesioner yang dibagikan.

\section{Uji Reliabilitas \& Uji Validitas}

Uji reliabilitas merupakan uji yang digunakan untuk mengukur konsistensi dari sebuah alat ukur. Reliabilitas adalah bagian dari suatu alat ukur dan mencerminkan kemampuan dari alat ukur dengan pelaksanaan berulang kali (Hicks, 2014). Pengujian reliabilitas dilakukan menggunakan koefisien alpha Cronbach $(\alpha)$. Batas nilai minimum alpha Cronbach agar suatu variabel laten dikatakan reliable adalah 0.6 (Griethuijsen et al., 2015)

Uji validitas merupakan uji yang digunakan untuk mengetahui apakah alat ukur yang digunakan memiliki kegunaan yang tepat untuk mengukur hal yang akan diukur.

\section{Metode Analisis Data}

Dalam penelitian ini, metode yang digunakan adalah Partial Least Square (PLS) dan Classification and Regression Tree (CART). Untuk dapat melakukan analisis dengan metode tersebut yang pertama kali dilakukan adalah membuat item kuesioner dan menyebarkannya dengan metode Purposive Sampling, selanjutnya dilakukan pengujian reliabilitas dan validitas. Setelahnya analisis menggunakan metode PLS dan CART dapat digunakan.

\section{Partial Least Square}

Partial Least Square (PLS) merupakan metode yang digunakan untuk mencari model hubungan antara suatu variabel laten dengan variabel laten lainnya dan hubungan antara variabel laten dengan item-itemnya (Hair et al., 2017). PLS tidak memiliki asumsi distribusi dan bekerja dengan baik pada data dengan ukuran sampel yang kecil. PLS digunakan untuk penelitian eksploratori. Metode PLS dapat digunakan untuk model pengukuran reflektif ataupun model pengukuran formatif. PLS juga dapat digunakan untuk model yang kompleks (model yang memiliki banyak item, variabel laten, serta hubungan antar variabel laten), namun PLS tidak dapat digunakan ketika di dalam model terdapat hubungan berbentuk loop antar variabel laten (Hair et al., 2017).

Tujuan utama dari adanya penelitian ini adalah mencari faktor-faktor yang berpengaruh secara signifikan terhadap kompetensi karyawan SOS Children's Villages Indonesia. Untuk mendapatkan hasil dari tujuan tersebut, variabel yang digunakan dalam analisis ini adalah seluruh variabel laten yang ada, sehingga dibutuhkan metode yang cocok untuk mengetahui model terbaik yang dibentuk. Selain itu, karena data yang dimiliki memiliki ukuran sampel yang relatif kecil, memiliki pengukuran reflektif, dan merupakan penelitian eksploratori, sehingga metode yang tepat digunakan untuk analisis ini merupakan metode Partial Least Square (PLS).

\section{Estimasi Parameter Model}

Model Partial Least Square menggabungkan item-item untuk membentuk estimasi skor dari variabel laten terkait. Setelah estimasi skor dari variabel laten didapatkan, selanjutnya dilakukan estimasi untuk memberikan penaksiran bagi outer model dan inner model. Estimasi parameter ini digunakan untuk menaksir outer loading, outer weight, dan koefisien jalur yang terdapat di dalam model.

Dikarenakan di dalam metode PLS tidak memiliki asumsi distribusi, maka estimasi parameter yang dilakukan tidak dapat diuji. Oleh karena itu, parameter diestimasi menggunakan iterasi dan pengujian dilakukan menggunakan metode bootstrap. Langkah dalam melakukan estimasi parameter menggunakan iterasi pada metode PLS terurai sebagai berikut (Sanchez, 2013):

1. Memberikan bobot pada item untuk untuk mendapatkan skor dari variabel laten terkait. Nilai bobot awal yang diberikan adalah sembarang, misal bobot awal $1\left(w_{i j}=1\right)$. 
2. Melakukan standardisasi untuk observasi ke- $h$ pada item ke-j dari variabel laten $i$.

3. Menghitung nilai outer estimation dari variabel laten. Persamaan 1 menunjukkan rumus untuk menghitung nilai outer estimation $y_{i h}$ dengan item sebanyak $p_{i}$ (Sanchez, 2013).

$$
\mathrm{y}_{\mathrm{ih}}=\sum_{\mathrm{j}=1}^{p_{\mathrm{i}}} \mathrm{w}_{\mathrm{ij}} \mathrm{x}_{\mathrm{ijh}}
$$

4. Melakukan standardisasi untuk variabel laten $y_{i h}$.

5. Menghitung nilai inner weight yang merupakan bobot yang terdapat di dalam setiap hubungan antar variabel laten. Persamaan 2 menunjukkan rumus perhitungan nilai inner weight antara variabel laten $i$ dan variabel laten $k$ dengan notasi $e_{i k}$ (Sanchez, 2013).

$$
\mathrm{e}_{\mathrm{ik}}=\left(\dot{y}_{\mathrm{k}} \mathrm{y}_{\mathrm{k}}\right)^{-1} \mathbf{y}_{\mathrm{k}}^{\prime} \dot{y}_{\mathrm{i}}
$$

6. Menghitung nilai inner estimation dari variabel laten $i$. Persamaan 3 menunjukkan rumus perhitungan inner estimation dari variabel laten $k$ yang berhubungan dengan variabel laten $i$ (Sanchez, 2013).

$$
\mathrm{z}_{\mathrm{ih}}=\sum_{\mathrm{k} \rightarrow \mathrm{i}} \mathrm{e}_{\mathrm{ik}} \dot{\mathrm{y}}_{\mathrm{ih}}
$$

7. Melakukan standardisasi dari nilai inner estimation $z_{i h}$.

8. Melakukan pembaruan nilai outer weight atau bobot untuk setiap item. Persamaan outer weight untuk model pengukuran reflektif dan model pengukuran formatif ditunjukkan pada Persamaan 4 dan 5 .

$$
\begin{gathered}
w_{i}=\left(\mathrm{z}_{\mathrm{i}}^{\prime} \mathrm{z}_{\mathrm{i}}\right)^{-1} \mathrm{z}_{\mathrm{i}}^{\prime} \mathrm{X}_{\mathrm{i}} \\
\mathbf{w}_{\mathrm{i}}=\left(\mathrm{X}_{\mathrm{i}}^{\prime} \mathrm{X}_{\mathrm{i}}\right)^{-1} \dot{\mathrm{X}}_{\mathrm{i}} \dot{\mathrm{z}}_{\mathrm{i}}
\end{gathered}
$$

9. Melakukan estimasi dari variabel laten dengan persamaan sebagai berikut.

$$
\tilde{y}_{i h}=y_{i h}=\sum_{j=1}^{p_{i}} w_{i j} \tilde{x}_{i j h}
$$

10. Melakukan estimasi untuk nilai koefisien jalur $\left(\beta_{\mathrm{ilk}}\right)$ dengan persamaan

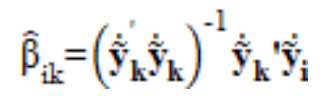

11. Melakukan estimasi untuk nilai loading $\lambda_{\mathrm{ij}}$ dengan persamaan

$$
\tilde{\mathrm{i}}_{\mathrm{ij}}=\operatorname{corr}\left(\mathrm{X}_{\mathrm{ij}}, \stackrel{\overrightarrow{\mathrm{Y}}}{\mathrm{i}}\right)
$$

12. Melakukan estimasi untuk nilai cross loading dengan persamaan

$$
\text { Cross Loading }=\operatorname{corr}\left(\hat{\mathrm{X}}_{\mathrm{qj}}, \hat{\mathrm{Y}_{\mathrm{i}}}\right)
$$

\section{Evaluasi Model}

Terdapat dua evaluasi dalam model PLS yang akan dijelaskan dalam penelitian ini, yaitu evaluasi outer model dan evaluasi inner model. 
1. Evaluasi Outer Model

Komponen yang digunakan dalam melakukan evaluasi outer model untuk model pengukuran reflektif adalah validitas konvergen yang terdiri dari outer loading dan average variance extracted, composite reliability, dan validitas diskriminan.

a. Validitas konvergen digunakan untuk mengukur sejauh mana suatu item berkorelasi positif dengan item lain dalam variabel laten terkait. Untuk mengukur validitas konvergen, digunakan nilai outer loading dari item dan nilai Average Variance Extracted (AVE).

Outer loading adalah korelasi antara masing-masing item dengan variabel laten terkait. Nilai outer loading minimum yang diharapkan adalah 0.6 (Hair et al., 2017). Average Variance Extracted (AVE) digunakan untuk mengetahui sejauh mana varians variabel laten dapat menjelaskan item-itemnya (Hair et al., 2017). Nilai AVE didapatkan melalui rata-rata dari kuadrat nilai outer loading. Nilai minimum AVE yang diharapkan adalah 0.5 (Hair et al., 2017).

b. Composite reliability digunakan untuk mengukur konsistensi dari sebuah variabel laten. Nilai composite reliability berada pada rentang 0 hingga 1 , dengan semakin tinggi nilai dari composite reliability maka semakin baik nilai reliabilitas yang dimiliki. Nilai minimum yang dibutuhkan dari composite reliability untuk penelitian eksploratori adalah 0.6 (Chin (1998), Hok dan Ringle (2006) dalam Garson, 2016).

c. Validitas diskriminan digunakan untuk menguji korelasi antara item-item yang terdapat pada suatu variabel laten dengan item-item pada variabel laten lainnya, maka yang diharapkan dari uji validitas diskriminan adalah masing-masing item memiliki korelasi yang kuat dengan variabel laten terkait dan memiliki korelasi yang rendah antara itemitem pada suatu variabel laten dengan variabel laten lainnya (Hair et al., 2017).

Cara untuk mengetahui nilai validitas diskriminan adalah dengan melihat nilai cross loading yang dimiliki setiap item. Cross loading merupakan nilai loading item dengan variabel laten yang tidak terkait dengan item tersebut. Nilai loading dari item-item dalam variabel laten terkait (outer loading) harus lebih besar dibanding nilai loading dengan variabel laten lainnya (cross loading). Apabila nilai dari cross loading melebihi nilai outer loading item, maka terdapat permasalahan dari validitas diskriminan (Hair et al., 2017).

2. Evaluasi Inner Model

Evaluasi inner model bertujuan untuk mengetahui hubungan yang terbentuk antar variabel laten. Untuk mengevaluasi inner model digunakan koefisien jalur dan koefisien determinasi $\left(\mathrm{R}^{2}\right)$.

a. Koefisien jalur menunjukkan hubungan antara masing-masing variabel laten dengan variabel laten endogen. Nilai koefisien jalur berada pada rentang -1 hingga +1 . Jika nilai koefisien jalur yang didapatkan dekat dengan nilai -1, maka dapat dinyatakan bahwa terdapat hubungan negatif yang kuat, begitu pula sebaliknya. Nilai yang mendekati 0 menunjukkan bahwa hubungan yang terjadi lemah (Hair et al., 2017).

b. Koefisien determinasi merupakan persentase varians dari variabel laten endogen yang dijelaskan oleh variabel laten lainnya di dalam inner model (Hair et al., 2017). Koefisien determinasi digunakan untuk mengukur akurasi dari sebuah model. Nilai dari koefisien determinasi berada pada rentang 0 hingga 1 . Nilai koefisien determinasi yang mendekati 1 menunjukkan bahwa model semakin baik, dengan kata lain semakin besar varians dari variabel laten endogen yang dijelaskan oleh variabel laten lainnya.

\section{Classification and Regression Tree}

Classification and Regression Tree (CART) merupakan salah satu metode pohon keputusan. Pohon keputusan merupakan metode yang berbentuk struktur diagram pohon, yang berguna sebagai alat pendukung pengambilan keputusan dalam prediksi klasifikasi observasi. Klasifikasi pada data dilakukan untuk mengelompokkan kasus-kasus berdasarkan nilai dari variabel independen. CART 
tidak memiliki asumsi distribusi, sehingga termasuk ke dalam metode nonparametrik. Metode pohon regresi digunakan apabila variabel dependen berupa variabel numerik, sementara metode pohon klasifikasi digunakan apabila variabel dependen berupa variabel kategorik (Breiman et al., 2017). Pada penelitian ini, variabel dependen yang digunakan merupakan variabel kategorik, sehingga akan digunakan metode pohon klasifikasi dalam analisis data.

\section{Langkah-langkah Pembentukan Pohon Klasifikasi}

a. Tahap Pembelahan

Pembelahan dengan metode CART mula-mula dilakukan pada simpul awal yang berisikan observasi yang masih bersifat heterogen, pembelahan dilakukan untuk mengurangi tingkat heterogen yang dimiliki. Penelitian ini menggunakan index gini untuk menghitung tingkat heterogenitas. Persamaan untuk menghitung index gini adalah:

$$
\operatorname{Gini}(t)=1-\sum_{i=1}^{k} p_{i}(t)^{2}
$$

dengan,

$$
p_{i}(t)=\frac{N_{i}(t)}{N(t)}
$$

Langkah selanjutnya adalah menghitung kriteria goodness of split dari pohon klasifikasi menggunakan nilai Gini $(t)$. Misalkan suatu simpul $t$ terbelah menjadi dua simpul, yaitu simpul kanan (R) dan simpul kiri (L). Rumus perhitungan goodness of fit adalah:

$$
\Delta \operatorname{Gini}(s, t)=\operatorname{Gini}(t)-p_{L} \operatorname{Gini}\left(t_{L}\right)-p_{\mathbb{R}} \operatorname{Gini}\left(t_{R}\right)
$$

Goodness of split menunjukkan seberapa baik pembelahan yang dilakukan. Semakin tinggi nilai $\Delta G i n i(s, t)$ maka pembelahan semakin baik, hal ini dikarenakan penurunan tingkat keheterogenan semakin tinggi.

b. Penentuan Simpul Akhir

Simpul akhir didapatkan ketika nilai heterogenitas sudah tidak menurun secara signifikan atau jika terdapat kriteria lain yang telah ditentukan.

c. Penandaan Label Kelas

Simpul akhir didapatkan ketika nilai heterogenitas sudah tidak menurun secara signifikan atau jika terdapat kriteria lain yang telah ditentukan.

\section{HASIL DAN PEMBAHASAN}

\section{Instrumen Penelitian}

Instrumen penelitian yang digunakan adalah beberapa kuesioner yang berisi pertanyaan dan pernyataan yang akan dijawab sesuai dengan tingkat kesetujuan responden. Pertanyaan dan pernyataan dibuat berdasarkan variabel yang akan diteliti. Variabel yang terlibat dalam penelitian adalah variabel usia, variabel tingkat pendidikan, dan variabel tempat bekerja yang dijawab dengan memilih satu pilihan jawaban yang sesuai dengan kondisi responden. Sedangkan variabel kompetensi, berpikir kritis, kepemimpinan, interpersonal, intrapersonal, kreativitas, dan inovasi merupakan variabelvariabel laten yang diukur dengan item-item. Seluruh item dari masing-masing variabel laten 
merupakan cerminan dari variabel laten tersebut. Item kuesioner yang digunakan dalam penelitian ini terdapat pada TABEL 1 .

TABEL 1. Item Kuesioner yang Digunakan dalam Penelitian

\begin{tabular}{|c|c|}
\hline Variabel Laten & Item Kuesioner \\
\hline Kompetensi & $\begin{array}{l}\text { Ketika mengerjakan project atau tugas, saya mengerjakan dengan sungguh-sungguh. } \\
\text { Saya memahami tugas yang saya kerjakan. } \\
\text { Saya memiliki semangat yang tinggi ketika berusaha mencapai target kerja. } \\
\text { Tugas yang saya kerjakan terselesaikan dengan sangat baik. } \\
\text { Saya menyelesaikan tugas jauh sebelum deadline pengumpulan. } \\
\text { Saya memiliki komitmen yang tinggi terhadap perusahaan. } \\
\text { Saya mengerti pengetahuan apa yang harus saya miliki dalam menyelesaikan tugas. } \\
\text { Dalam pekerjaan, saya menerapkan asas profesionalitas. }\end{array}$ \\
\hline Berpikir Kritis & $\begin{array}{l}\text { Saya dapat mengidentifikasi pertanyaan dari kasus yang diberikan. } \\
\text { Ketika berhadapan dengan sebuah pertanyaan, saya memikirkan beberapa jawaban yang } \\
\text { mungkin. } \\
\text { Saya dapat memikirkan kesimpulan atau konklusi dari suatu kasus. } \\
\text { Saya dapat melakukan observasi dan mengecek kredibilitas dari berita yang muncul. } \\
\text { Saya menghormati sudut pandang orang lain . } \\
\text { Keputusan yang saya ambil didasarkan oleh beberapa pertimbangan. } \\
\text { Saya melakukan evaluasi terhadap hasil pemikiran saya. }\end{array}$ \\
\hline Kepemimpinan & $\begin{array}{l}\text { Saya berani mengambil risiko untuk mewujudkan tujuan dari perusahaan. } \\
\text { Saya melakukan pekerjaan secara maksimal agar menjadi contoh yang baik bagi rekan kerja } \\
\text { saya. } \\
\text { Saya dapat membuat keputusan dengan bijak. } \\
\text { Saya dapat memberi motivasi yang membangun terhadap rekan kerja saya. } \\
\text { Saya memiliki kemampuan untuk mengatur hal agar berjalan dengan baik. } \\
\text { Saya dapat memberi pengaruh terhadap orang lain. } \\
\text { Jika saya menjadi pemimpin, saya akan secara aktif memantau kinerja rekan kerja saya. }\end{array}$ \\
\hline Interpersonal & $\begin{array}{l}\text { Saya dapat mengendalikan emosi negatif berlebihan yang saya miliki (marah, cemas, sedih, } \\
\text { jengkel, dsb). } \\
\text { Saya mengerti perasaan yang orang lain rasakan. } \\
\text { Saya dapat melakukan persuasi sehingga ide yang saya salurkan dapat digunakan. } \\
\text { Saya dapat menyampaikan opini dan hal yang dirasakan ketika berbicara mengenai situasi } \\
\text { yang spesifik. } \\
\text { Saat ada orang yang membantah argumen saya, saya tidak merasa terpojokkan. } \\
\text { Menurut saya, proses diskusi dalam bekerja adalah hal penting dan harus dilakukan. } \\
\text { Saya dapat menerima masukan ataupun kritik dengan pemikiran terbuka. } \\
\text { Rekan kerja saya dapat mengandalkan saya. }\end{array}$ \\
\hline Intrapersonal & $\begin{array}{l}\text { Saya memahami apa yang saya inginkan. } \\
\text { Saya mampu memotivasi diri sendiri untuk menjadi lebih baik. } \\
\text { Saya mengambil pelajaran yang positif dalam situasi apapun. } \\
\text { Saya melakukan introspeksi terhadap perilaku yang saya lakukan. } \\
\text { Saya menganggap kegagalan adalah sebuah pembelajaran. } \\
\text { Saya seringkali melakukan pencarian untuk menemukan jati diri saya sendiri. } \\
\text { Saya dapat mengatur waktu yang saya gunakan sehari-hari dengan baik. } \\
\text { Saya mengetahui dan dapat mengendalikan hal yang membuat saya mengalami stress. }\end{array}$ \\
\hline Kreativitas & $\begin{array}{l}\text { Saya sering terpikirkan ide baru untuk menciptakan sesuatu yang baru. } \\
\text { Saya dapat melihat suatu masalah dari berbagai sudut pandang. } \\
\text { Saya dapat berpikir secara imajinatif dan penuh dengan strategi. } \\
\text { Saya memecahkan masalah dengan berpikir berbeda dari yang lain (out of the box). } \\
\text { Saya dapat mengidentifikasi bagaimana kualitas ataupun kuantitas suatu hal dapat } \\
\text { ditingkatkan. } \\
\text { Adanya tantangan memacu saya untuk menjadi lebih bersemangat. } \\
\text { Ide yang saya keluarkan seringkali merupakan gagasan asli hasil pemikiran sendiri disini. }\end{array}$ \\
\hline Inovasi & $\begin{array}{l}\text { Saya sering menerapkan ide yang saya berikan kepada perusahaan. } \\
\text { Saya mengetahui apa saja yang dibutuhkan dalam mengubah ide menjadi sebuah aksi yang }\end{array}$ \\
\hline
\end{tabular}


dilakukan.

Saya mencoba menggabungkan ide saya dengan ide lain agar menciptakan sebuah produk yang berguna.

Saya memiliki kemampuan untuk memilih ide mana yang sesuai dengan tujuan perusahaan. Saya mampu menerjemahkan sesuatu yang abstrak menjadi sesuatu yang penuh arti.

Saya senang membuat perubahan, meskipun perubahan itu kecil.

Saya sering menerapkan ide yang saya berikan kepada perusahaan.

\section{Uji Reliabilitas}

TABEL 2. Nilai Koefisien alpha Cronbach dari Setiap Variabel Laten

\begin{tabular}{cc}
\hline Variabel Laten & alpha Cronbach \\
\hline Kompetensi & 0,811 \\
Berpikir Kritis & 0,814 \\
Kepemimpinan & 0,843 \\
Interpersonal & 0,765 \\
Intrapersonal & 0,779 \\
Kreativitas & 0,800 \\
Inovasi & 0,824 \\
\hline
\end{tabular}

Berdasarkan hasil uji reliabilitas pada TABEL 2 menggunakan alpha Cronbach, diperoleh hasil bahwa seluruh nilai koefisien alpha Cronbach memiliki nilai yang lebih besar dari 0,6. Sehingga dapat dinyatakan bahwa seluruh variabel laten reliable.

\section{Uji Validitas}

TABEL 3. Nilai Sperman's Rho dari Item pada Setiap Variabel Laten

\begin{tabular}{ccccccccc}
\hline \multirow{2}{*}{ Variabel Laten } & \multicolumn{1}{c}{ Spearman's rho Sig. } \\
\cline { 2 - 8 } & Item 1 & Item 2 & Item 3 & Item 4 & Item 5 & Item 6 & Item 7 & Item 8 \\
\hline Kompetensi & 0.00 & 0.00 & 0.00 & 0.00 & 0.00 & 0.00 & 0.00 & 0.00 \\
Berpikir Kritis & 0.00 & 0.00 & 0.00 & 0.00 & 0.00 & 0.00 & 0.00 & - \\
Kepemimpinan & 0.00 & 0.00 & 0.00 & 0.00 & 0.00 & 0.00 & 0.00 & - \\
Interpersonal & 0.00 & 0.00 & 0.00 & 0.00 & 0.00 & 0.00 & 0.00 & 0.00 \\
Intrapersonal & 0.00 & 0.00 & 0.00 & 0.00 & 0.00 & 0.00 & 0.00 & 0.00 \\
Kreativitas & 0.00 & 0.00 & 0.00 & 0.00 & 0.00 & 0.00 & 0.00 & - \\
Inovasi & 0.00 & 0.00 & 0.00 & 0.00 & 0.00 & 0.00 & - & - \\
\hline
\end{tabular}

Berdasarkan hasil uji validitas pada TABEL 3 menggunakan Spearman's rho diperoleh hasil bahwa terdapat korelasi antara item ke- $j$ dengan total skor variabel laten terkait atau dapat dinyatakan bahwa variabel kompetensi, berpikir kritis, kepemimpinan, interpersonal, intrapersonal, kreativitas, dan inovasi adalah valid.

\section{Partial Least Square}

Setelah dilakukan uji reliabilitas dan uji validitas, selanjutnya dilakukan pengolahan data menggunakan metode Partial Least Square untuk mengetahui faktor yang secara signifikan memengaruhi kompetensi karyawan di SOS Children's Villages Indonesia. Model awal yang didapatkan menggunakan metode Partial Least Square terdapat pada GAMBAR 1. 


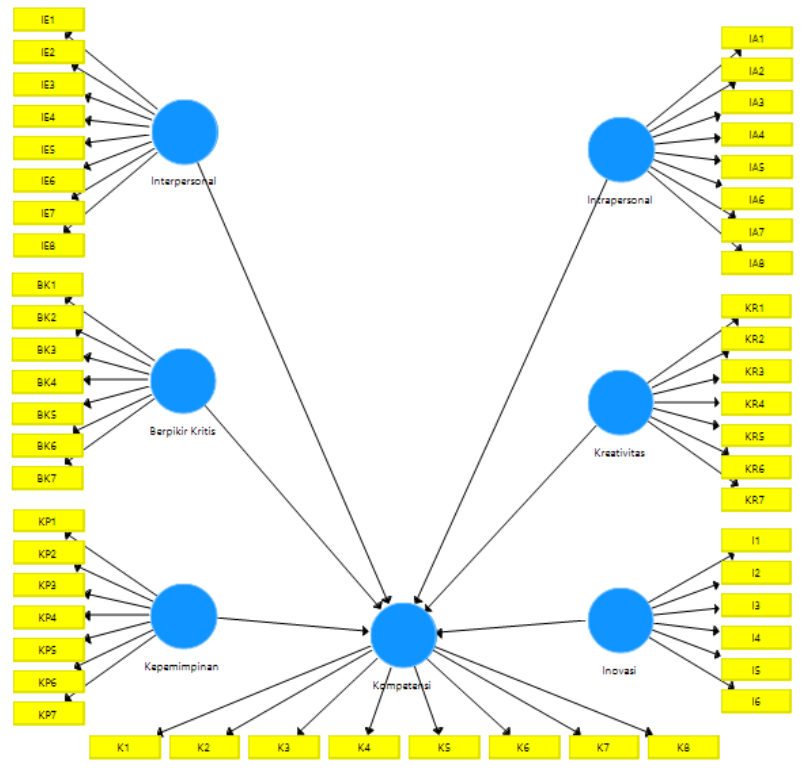

GAMBAR 1. Model Awal Partial Least Square

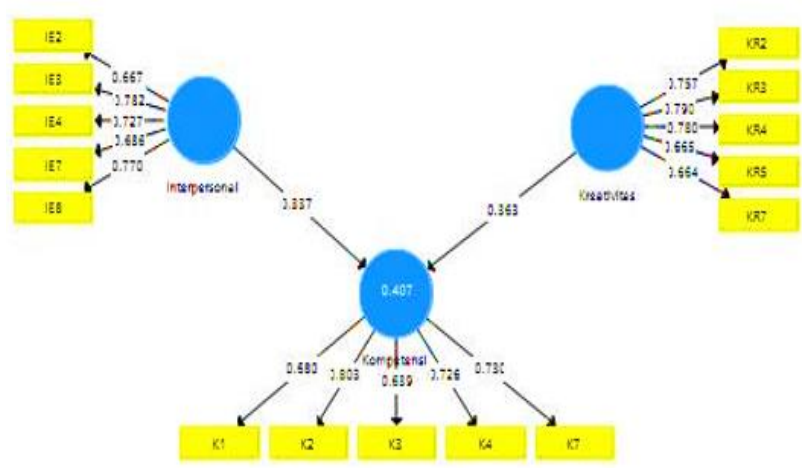

GAMBAR 2. Model Terbaik Partial Least Square

Setelah model awal ditetapkan, langkah selanjutnya adalah mencari taksiran parameter dari model tersebut. Model akan dievaluasi secara terus-menerus melalui evaluasi outer model dan evaluasi inner model hingga didapatkan model terbaik. Visualisasi model terbaik sebagai model akhir ditunjukkan pada GAMBAR 2, dengan hasil yaitu faktor yang secara signifikan memengaruhi kompetensi adalah interpersonal dan kreativitas.

Nilai Outer Loading yang diperoleh berdasarkan evaluasi dari model terbaik Partial Least Square adalah sebagai berikut.

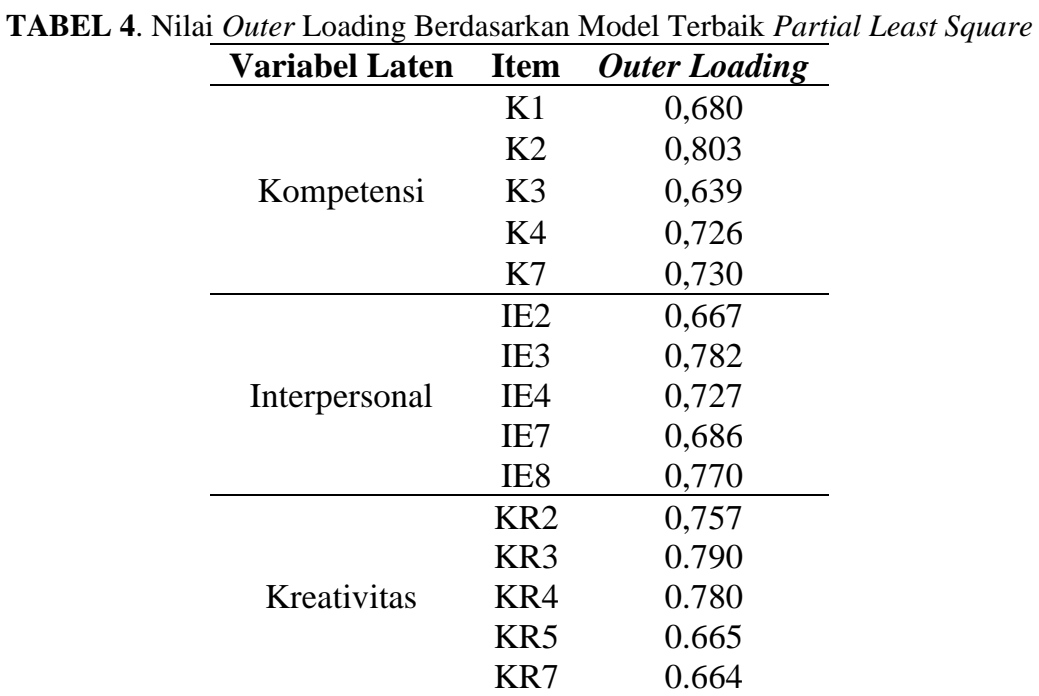

Berdasarkan nilai outer loading yang tertera pada TABEL 4, ditunjukkan bahwa seluruh nilai outer loading masing-masing item pada variabel laten lebih besar dari batas minimum yang telah ditentukan, yaitu 0,6. Sehingga dapat dikatakan bahwa hubungan antara item-item dengan variabel laten terkait baik.

Nilai Average Variance Extracted (AVE) berdasarkan model terbaik Partial Least Square dituliskan pada TABEL 5 di bawah ini. 
TABEL 5. Nilai Average Variance Extracted Item Variabel Laten pada Model Terbaik Partial Least Square

\begin{tabular}{cc}
\hline Variabel Laten & $\begin{array}{c}\text { Average Variance } \\
\text { Extracted }(\mathrm{AVE})\end{array}$ \\
\hline Kompetensi & 0,515 \\
Interpersonal & 0.529 \\
Kreativitas & 0,537 \\
\hline
\end{tabular}

Berdasarkan hasil nilai AVE yang tertera dalam TABEL 5, variabel laten memiliki nilai yang lebih besar dari 0,5 , sehingga memenuhi batas nilai minimum untuk AVE. Selanjutnya akan dilakukan perhitungan hasil composite reliability.

Nilai Composite Reliability berdasarkan model terbaik Partial Least Square adalah sebagai berikut.

TABEL 6. Nilai Composite Reliability Variabel Laten pada Model Terbaik Partial Least Square

\begin{tabular}{cc} 
Variabel Laten & Composite Reliability \\
\hline Kompetensi & 0,841 \\
Interpersonal & 0,834 \\
Kreativitas & 0,852 \\
\hline
\end{tabular}

Berdasarkan hasil nilai composite reliability yang tertera pada TABEL 6, ditunjukkan bahwa seluruh nilai composite reliability lebih besar dari nilai minimum 0,6 . Sehingga dapat dikatakan bahwa item-item di dalam variabel laten yang terkait memiliki internal konsistensi yang baik.

Dikarenakan hasil evaluasi yang diperoleh pada model terbaik Partial Least Square telah memenuhi batas minimum, selanjutnya menghitung nilai koefisien determinasi dari model tersebut. Nilai koefisien determinasi $\left(\mathrm{R}^{2}\right)$ yang diperoleh dari model terbaik Partial Least Square ditunjukkan sebagai berikut.

TABEL 7. Nilai Koefisien Determinasi dari Model Terbaik Partial Least Square

\begin{tabular}{cc}
\hline Variabel Laten & $\begin{array}{c}\text { Koefisien } \\
\text { Determinasi }\end{array}$ \\
\hline Competency & 0.407 \\
\hline
\end{tabular}

Berdasarkan TABEL 7, ditunjukkan bahwa nilai koefisien determinasi adalah sebesar 0,407. Atau dengan kata lain bahwa sebesar 40,7\% varians dari variabel kompetensi dapat dijelaskan dengan baik oleh variabel interpersonal dan variabel kreativitas. Nilai $\mathrm{R}^{2}$ yang diperoleh termasuk ke dalam kategori sedang (Sanchez, 2013). 


\section{Classification and Regression Tree}

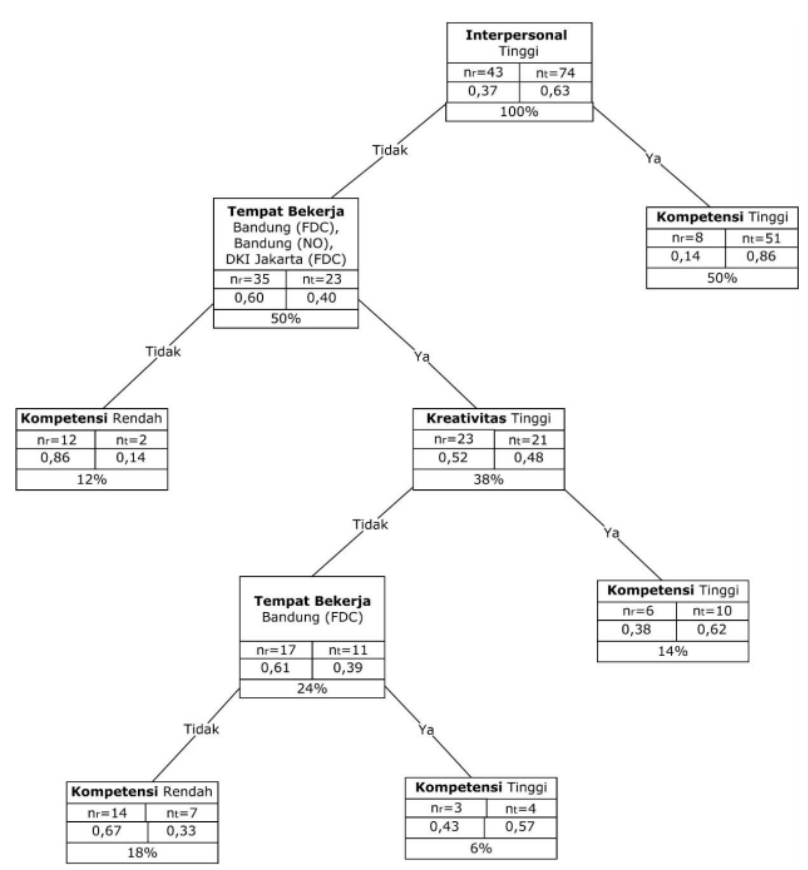

GAMBAR 3. Model Terbaik Partial Least Square

Berdasarkan GAMBAR 3, dapat diketahui profil dari karyawan dengan kompetensi yang tinggi diuraikan sebagai berikut.

1. Berdasarkan metode CART menggunakan data yang telah dikategorikan, variabel yang paling kuat memengaruhi variabel kompetensi adalah variabel interpersonal. Jika tingkat interpersonal dari karyawan tinggi, maka probabilitas karyawan untuk memiliki kompetensi tinggi adalah 0.86. Hal ini menunjukkan bahwa $86 \%$ dari karyawan dengan interpersonal tinggi memiliki kecenderungan untuk memiliki kompetensi yang tinggi. Jika karyawan memiliki tingkat interpersonal yang rendah, klasifikasi berikutnya akan dilihat berdasarkan tempat bekerja dari karyawan tersebut.

2. Karyawan dengan tingkat interpersonal rendah yang bekerja di kantor Fund Development and Communication yang terletak di DI Yogyakarta, Surabaya, dan Bali memiliki kecenderungan untuk memiliki kompetensi rendah, yaitu sebesar 0.86 . Hal ini menunjukkan bahwa $86 \%$ dari karyawan dengan tingkat interpersonal rendah dan bekerja di tempat tersebut cenderung memiliki kompetensi yang rendah. Jika karyawan bekerja di kantor Fund Development and Communication yang terletak di DKI Jakarta dan Bandung, serta kantor National Office yang terletak di Bandung, selanjutnya akan dilihat berdasarkan tingkat kreativitas karyawan tersebut.

3. Karyawan yang bekerja di kantor Fund Development and Communication yang terletak di DKI Jakarta dan Bandung, serta kantor National Office yang terletak di Bandung dengan tingkat interpersonal rendah dan kreativitas tinggi memiliki probabilitas yang lebih besar untuk memiliki kompetensi tinggi, yaitu sebesar 0.62. Hal ini menunjukkan bahwa $62 \%$ dari karyawan dengan karakteristik tersebut memiliki kecenderungan untuk memiliki kompetensi tinggi. Sementara karyawan dengan tingkat kreativitas rendah selanjutnya akan dilihat berdasarkan tempat bekerja. Apabila karyawan tersebut bekerja di kantor Fund Development and Communication yang terletak di Bandung, maka probabilitas untuk memiliki kompetensi tinggi lebih besar, yaitu sebesar 0.57, namun jika karyawan bekerja di kantor Fund Development and Communication yang terletak di DKI Jakarta dan kantor National Office yang terletak di Bandung, maka karyawan tersebut memiliki probabilitas yang lebih besar untuk memiliki kompetensi rendah, yaitu sebesar 0.67. 
TABEL 8 menunjukkan akurasi dan kesesuaian yang didapatkan dari penentuan profil karyawan dengan kompetensi tinggi menggunakan pohon klasifikasi dengan metode Classification and Regression Tree.

TABEL 8. Akurasi dan Kesesuaian Metode Classification and Regression Tree

\begin{tabular}{lccc}
\hline \multirow{2}{*}{ Observed } & \multicolumn{3}{c}{ Predicted } \\
\cline { 2 - 4 } & Rendah & Tinggi & Percentage Correct \\
\hline Rendah & 26 & 17 & $60.5 \%$ \\
Tinggi & 9 & 65 & $87.8 \%$ \\
\hline Akurasi & & & $\mathbf{7 7 , 8 \%}$ \\
\hline
\end{tabular}

Berdasarkan hasil TABEL 8, ditunjukkan bahwa nilai persentase akurasi dari pohon klasifikasi dengan menggunakan metode Classification and Regression Tree adalah $77.8 \%$. Hal ini menunjukkan bahwa pohon klasifikasi dapat mengklasifikasikan sebesar $77.8 \%$ data dengan benar. Selain itu, nilai TPR yang diperoleh adalah $87.8 \%$ dan nilai TNR yang diperoleh adalah $60.5 \%$. Dalam penelitian ini, hasil pohon klasifikasi dinyatakan cukup baik, karena penelitian yang dilakukan merupakan penelitian psikologis yang mengukur perilaku dari karyawan yang dapat berbeda-beda antara satu karyawan dengan karyawan lainnya.

\section{KESIMPULAN}

Berdasarkan penelitian ini dapat disimpulkan bahwa faktor-faktor yang secara signifikan berpengaruh terhadap kompetensi karyawan SOS Children's Villages Indonesia adalah interpersonal dan kreativitas. Profil dari karyawan dengan kompetensi yang tinggi diperoleh sesuai dengan tujuan kedua dari penelitian, yaitu:

a. Karyawan dengan kemampuan interpersonal tinggi memiliki kecenderungan untuk memiliki tingkat kompetensi yang tinggi.

b. Karyawan yang bekerja di Bandung (NO), Bandung (FDC), dan DKI Jakarta (FDC) dengan tingkat kreativitas tinggi cenderung memiliki kompetensi yang tinggi. Selain itu, karyawan yang bekerja di Bandung (FDC), meskipun memiliki tingkat interpersonal dan kreativitas rendah, karyawan tersebut memiliki kecenderungan untuk memiliki kompetensi tinggi.

\section{UCAPAN TERIMA KASIH}

Penulis mengucapkan terima kasih kepada SOS Children's Villages Indonesia khususnya kepada para karyawan di kantor Fund Development and Communication dan kantor National Office yang telah mendukung penelitian ini terlaksana. Selanjutnya, penulis juga berterima kasih kepada pihakpihak yang telah ikut menyumbang ide, saran, dan dukungan sehingga penelitian ini dapat dilakukan sebagaimana mestinya.

\section{REFERENSI}

Almaki, S. H., Silong, A. D., Idris, K., \& Wahat, N. W. A. (2016). 'Understanding of the Meaning of Leadership from the Perspective of Muslim Women Academic Leaders'. Journal of Educational and Social Research, 6.

Bogenschneider, B. (2016). 'Leadership Epistemology'. Creighton Journal of Interdisciplinary Leadership, 2.

Breiman, L., Friedman, J. H., Olshen, R. A., \& Stone, C. J. (2017). 'Classification and Regression Trees'. Routledge. New York.

Chouhan, V. S., \& Srivastava, S. (2016). 'Understanding Competencies and Competency Modeling'. IOSR Journal of Business and Management (IOSR-JBM), 16.

Deveci, T., \& Nunn, R. (2018). 'Intrapersonal Communication As a Lifelong Learning Skill in Engineering Education'. Journal of Higher Education, 8. 
Fauzia, A. F. (2015). 'Pengaruh Usia, Pendapatan, Persepsi Manfaat, Gaya Hidup, dan Promosi Penjualan Terhadap Minat Masyarakat dalam Menggunakan Kartu Debet Untuk Bertransaksi Non Tunai (Studi Kasus Masyarakat Kota Surakarta)'. Skripsi. Program Sarjana Universitas IAIN Surakarta.

Garson, G. D. (2016). 'Partial Least Squares: Regression \& Structural Equation Models'. In Statistical Associates Publishing.

Hair, J. F., Hult, G. T. M., Ringle, C. M., \& Sarstedt, M. (2017). 'A Primer on Partial Least Squares Structural Equation Modeling (PLS-SEM)'. SAGE Publications, Inc (2 ed.).

Herdiansah, A. G., \& Randi. (2016). 'Peran Organisasi Masyarakat (Ormas) dan Lembaga Swadaya Masyarakat (LSM) dalam Menopang Pembangunan di Indonesia'. Sosioglobal: Jurnal Pemikiran dan Penelitian Sosiologi, 1.

Hicks, N. A. (2014). 'Establishing the Validity and Reliability of the Fairness of Items Tool'. ProQuest Dissertations and Theses.

Istikomah. (2016). 'Pengaruh Upah dan Lingkungan Kerja Terhadap Produktivitas Kerja Tenaga Kerja Langsung pada CV. Rimba Sentosa di Tawangsari Kabupaten Sukoharjo'. Skripsi

Kallet, M. (2014). 'Think Smarter: Critical Thinking to Improve Problem-Solving and DecisionMaker Skills'. Wiley \& Sons, Inc.

Michalik, A. (2017). 'Creative Competencies in Organization'. World Scientific News, 78.

National Association of Colleges and Employers. (2019). 'Career Readiness Defined'. Diambil 1 Februari 2020, dari https://www.naceweb.org/career-readiness/competencies/career-readinessdefined/.

Purnomo, D., \& Sudana, I. P. (2016). 'Pengaruh Pendidikan dan Pelatihan Terhadap Kompetensi Serta Dampaknya pada Kinerja Pramuwisata Bali'. IPTA, 4.

Quinn, K. A. (2013). 'The Importance of Resource and Interpersonal Skills in the Hospitality Industry'. Journal of Foodservice Business Research, 16(5).

Rai, N., \& Thapa, B. (2015). 'A Study on Purposive Sampling Method in Research'. Kathmandu:Kathmandu School of Law, 5.

Rajegunung, D. R. (2017). 'Membangun NGO yang Kuat'. Friedrich Naumann Stiftung. Diambil 13 April 2020, dari https://indonesia.fnst.org/content/membangun-ngo-yang-kuat

Ramadhan, S. R. (2013). 'Analisis Faktor-Faktor yang Mempengaruhi Produksi pada Tenaga Kerja (Studi Kasus CV. Mukkadimah Agro Medica Desa Sawahan Kecamatan Turen Kabupaten Malang)'. Universitas Brawijaya.

Sanchez, G. (2013). 'PLS Path Modeling with R'. Berkeley.

Santika, I. G. P. N. A. (2015). 'Hubungan Indeks Massa Tubuh (IMB) dan Umur Terhadap Daya Tahan Umum (Kardiovaskuler) Mahasiswa Putra Semester II Kelas A Fakultas Pendidikan Olahraga dan Kesehatan IKIP PGRI Bali Tahun 2014'.

SOS Children's Villages. (n.d.). 'Tentang Kami'. Diambil 10 Februari 2020, dari https://www.sos.or.id/tentang-sos

Szczepańska-Woszczyna, K. (2014). 'Competencies, Innovation and Entrepreneurship In The Theory and Practice of Management'. Dąrowa Górnicza.

Vijayalakshmi, D. V. (2016). Soft Skills-The Need of the Hour for Professional Competence: A Review on Interpersonal Skills and Intrapersonal Skills Theories. International Journal of Applied Engineering Research, 11.

Van Griethuijsen, R.A.L.F., Van Eijck, M.W., Haste, H. et al. (2015). Global Patterns in Students' Views of Science and Interest in Science. Res Sci Educ 45. 